\title{
Impact of Industry Payments on Prescribing Patterns for Tumor Necrosis Factor Inhibitors Among Medicare Beneficiaries
}

\author{
Partik Singh, BA ${ }^{7}$, Howard Forman, MD, MBA ${ }^{2}$, Adewole S. Adamson, MD, MPP , \\ Arash Mostaghimi, MD, MPA, MPH4 , Alexis R. Ogdie, MD, MSCE ${ }^{5}$, Arman Oganisian, $\mathrm{SS}^{6}$, and \\ John S. Barbieri, MD, MBA ${ }^{7}$

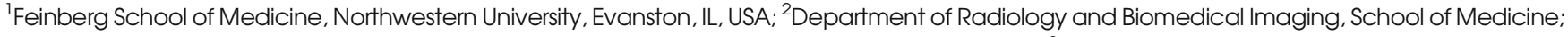 \\ Yale School of Public Health; Yale School of Management, Yale University, New Haven, CT, USA; ${ }^{3}$ Department of Internal Medicine, Dell Medical \\ School at The University of Texas at Austin, Austin, TX, USA; ${ }^{4}$ Department of Dermatology, Brigham and Women's Hospital, Boston, MA, USA; \\ ${ }^{5}$ Department of Rheumatology, University of Pennsylvania, Philadelphia, PA, USA; ${ }^{6}$ Division of Biostatistics, University of Pennsylvania, Philadelphia, \\ PA, USA; ${ }^{7}$ Department of Dermatology, University of Pennsylvania, Philadelphia, PA, USA.
}

J Gen Intern Med 34(2):176-8

DOI: $10.1007 / \mathrm{s} 11606-018-4698-\mathrm{x}$

(C) Society of General Internal Medicine 2018

\section{INTRODUCTION}

Industry payments (including in-kind) to physicians in the form of attendance of industry sponsored continuing medical education, gifts, and meals are associated with increased rates of prescription of higher-cost, branded medications. ${ }^{1-4}$ Whether industry payments are associated with preferential prescribing within a single class of brand medications is uncertain. We conducted a cross-sectional study to examine the association between industry payments and prescribing patterns for the branded tumor necrosis factor (TNF) inhibitors etanercept and adalimumab, which are in the same therapeutic class and have similar clinical indications.

\section{METHODS}

Data for providers in the Centers for Medicare \& Medicaid Services Medicare Part D public use file who prescribed either etanercept or adalimumab in 2015 were linked with Physician Compare data and Open Payments data from 2014 and 2015, using a unique identifier of provider name and city. Payments from the manufacturers of etanercept (Amgen) and adalimumab (AbbVie) were averaged over the 2 years of data. All specialties were included in the analysis, except for gastroenterologists who were excluded due to predominately prescribing only adalimumab. Multivariable Poisson regression was used to test for an association between whether the provider had received any payments from the associated man-

Prior Presentation: This work has not been previously published. Preliminary results from this work were presented as a poster at the 2018 International Investigative Dermatology Meeting, which was held May 1619,2018

Published online October 15, 2018 ufacturer and the relative percentage of prescribing between the two drugs. Separately, multivariable linear regression was used to test for an association between the difference in the number of claims for the two drugs (etanercept-adalimumab) and either the total value or number of industry payments. Both analyses controlled for provider type, gender, and years in clinical practice. This study was exempted from review by the University of Pennsylvania institutional review board.

\section{RESULTS}

Among 6440 clinicians who prescribed the TNF inhibitors etanercept and adalimumab, overall prescribing of these medications was higher among physicians who received payments compared to those who did not (Fig. 1). Among etanercept prescribers, those who received payments from the associated manufacturer prescribed etanercept more frequently than those who did not (relative percentage of prescribing $51.4 \%$ vs. $49.7 \%, p<0.001)$. Similarly, among adalimumab prescribers, those who received payments from the associated manufacturer prescribed adalimumab more frequently than those who did not (relative percentage of prescribing $49.7 \%$ vs. $45.1 \%, p<0.001$ ). In subgroup analyses, this association was more pronounced among rheumatologists than dermatologists (Fig. 1).

Larger and higher numbers of payments from Amgen were associated with increased prescribing of etanercept with, on average, each $\$ 100$ received being associated with 0.57 more etanercept claims $(p<0.001)$. Larger and higher numbers of payments from AbbVie were associated with increased prescribing of adalimumab with, on average, each $\$ 100$ received being associated with 0.37 more adalimumab claims $(p<0.001)$ (Table 1). More years in practice were associated with more frequent etanercept prescribing $(p<0.001)$. Rheumatologists had more frequent interactions with industry than dermatologists (median number of payments per provider 9 versus 3). 

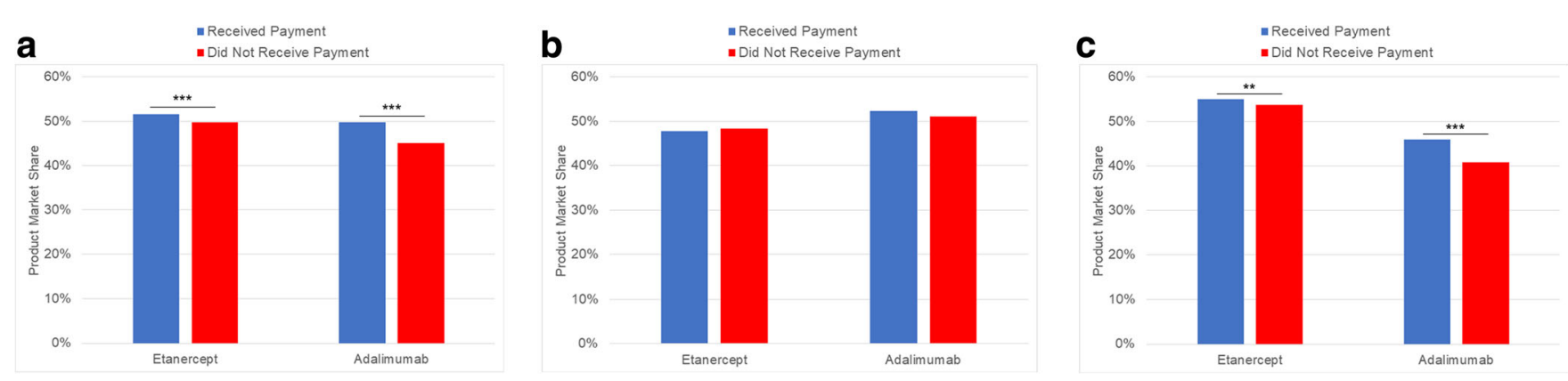

Figure 1 TNF inhibitor market share and relevant industry payments. Multivariable Poisson regression was used to estimate the association between receipt of manufacturer payments and physicians' prescribing of that manufacturer's drug for a all physicians, $b$ dermatologists, and $c$ rheumatologists. Each bar represents the relative percentage of prescribing between the two drugs. Physicians who received payments from the manufacturer of the drug of interest are shown in blue; physicians who did not are shown in red. Results are adjusted for physician years in practice, sex, and medical specialty and presented at the mean values for these variables. $P$ values are adjusted for multiple hypotheses testing in subgroup analyses using the Bonferroni method. $* * p<0.01 ; * * p<0.001$.

\section{DISCUSSION}

These findings highlight a modest association between frequency and value of industry payments and prescribing volume of associated TNF inhibitors, which persists after controlling for physician specialty, gender, and years in practice.
Given the high-cost of these medications, these associations may be meaningful to the health system. In addition, given the profitability of these medications relative to the estimated payment associated with one additional claim, the return on investment for these industry payments is likely to be high. ${ }^{5}$

Table 1 Provider and Payment Characteristics

\begin{tabular}{|c|c|}
\hline Female sex $(\%)$ & $2253(34.8)$ \\
\hline Years in practice, years (IQR) & $25(15-34)$ \\
\hline \multicolumn{2}{|l|}{ Specialty } \\
\hline Dermatology $(\%)$ & 3007 (46.4) \\
\hline Rheumatology (\%) & $2163(33.4)$ \\
\hline Internal medicine (\%) & $735(11.3)$ \\
\hline Other provider $(\%)$ & $575(8.9)$ \\
\hline Number claims Etanercept, median (IQR) & $11(9-35)$ \\
\hline Number claims Adalimumab, median (IQR) & $11(9-30)$ \\
\hline Percentage of payments for food and beverage & $91.8 \%$ \\
\hline Percentage of payments for education & $1.4 \%$ \\
\hline Percentage of payments for consulting fees & $0.2 \%$ \\
\hline Percentage of payments for travel and lodging & $6.3 \%$ \\
\hline Percentage of other payments & $0.3 \%$ \\
\hline Total payment Amgen per Provider, median (IQR), \$ & $58.20(19.94-142.68)$ \\
\hline Total payment AbbVie per Provider, median (IQR), \$ & $86.45(30.17-210.09)$ \\
\hline Average payment Amgen per Provider, median (IQR), \$ & $16.22(13.24-23.03)$ \\
\hline Average payment AbbVie per Provider, median (IQR), $\$$ & $18.34(14.68-30.29)$ \\
\hline Number payments Amgen per Provider, median (IQR) & $3(1-8)$ \\
\hline Number payments AbbVie per Provider, median (IQR) & $4(1-11)$ \\
\hline \multirow{2}{*}{\multicolumn{2}{|c|}{$\begin{array}{l}\text { Predictors of TNF inhibitor prescribing } \\
\text { Payment valuet }\end{array}$}} \\
\hline & \\
\hline Payments AbbVie, \$ (95\% CI) & $-0.0037(-0.0054$ to -0.0020$) * * *$ \\
\hline Payments Amgen, \$ (95\% CI) & $0.0057(0.0024$ to 0.0091$) * * *$ \\
\hline Female sex $(95 \% \mathrm{CI})$ & $-4.76(-6.49$ to -3.02$) * * *$ \\
\hline Years in practice $(95 \% \mathrm{CI})$ & $0.19(0.13$ to 0.26$) * * *$ \\
\hline \multicolumn{2}{|l|}{ Specialty } \\
\hline Dermatology & [Reference] \\
\hline Rheumatology $(95 \%$ CI) & 47.09 (44.85 to 49.33$) * * *$ \\
\hline Internal medicine $(95 \% \mathrm{CI})$ & $13.92(11.07$ to 16.78$) * * *$ \\
\hline Other $(95 \% \mathrm{CI})$ & $-0.83(-2.01$ to 0.34$)$ \\
\hline \multicolumn{2}{|l|}{ Number of payments $\dagger$} \\
\hline Number payments AbbVie $(95 \% \mathrm{CI})$ & $-0.61(-0.78$ to -0.45$) * * *$ \\
\hline Number payments Amgen (95\% CI) & $0.93(0.73$ to 1.14$) * * *$ \\
\hline Female sex $(95 \% \mathrm{CI})$ & $-3.80(-5.50$ to -2.10$) * * *$ \\
\hline Years in practice $(95 \% \mathrm{CI})$ & $0.18(0.12 \text { to } 0.24)^{* * *}$ \\
\hline \multicolumn{2}{|l|}{ Specialty } \\
\hline Dermatology & [Reference] \\
\hline Rheumatology $(95 \%$ CI) & $43.29(40.95$ to 45.64$) * * *$ \\
\hline Internal medicine $(95 \% \mathrm{CI})$ & $13.58(10.88$ to 16.28$) * * *$ \\
\hline Other $(95 \% \mathrm{CI})$ & $0.65(-0.59$ to 1.88$)$ \\
\hline
\end{tabular}

† Results reflect differences between the number of claims for the two drugs (etanercept-adalimumab). $\beta$ coefficients for the value and number of payments are presented after adjusting for physician years in practice, sex, and medical specialty. Italic values indicate statistical significance: $* * * p<0.001$ 
This association was more pronounced among rheumatologists than dermatologists, which may be related to increased industry interaction among rheumatologists, fewer total prescriptions written by dermatologists, or stronger baseline prescribing preferences among dermatologists, among other factors. Physicians who have been in practice longer were more likely to prescribe etanercept, which may be related to the earlier introduction of etanercept.

There are many potential factors by which industry payments could potentially impact prescribing volume for associated drugs. For instance, it is possible that this association may reflect a positive educational effect in which industry interactions cause physicians to become more comfortable with appropriate use of these medications. However, it is also possible that industry interactions could reflect a negative distortionary effect potentially related to rewarding prescribing behavior. ${ }^{6}$ Additional research is needed to understand the underlying factors responsible for this association and the implications for patient outcomes and health care expenditures.

Contributors: None.

Corresponding Author: John S. Barbieri, MD, MBA; Department of Dermatology University of Pennsylvania, 2 Maloney, 3600 Spruce Street, Philadelphia, PA 19104, USA (e-mail: john.barbieri@uphs. upenn.edu).
Funding Dr. Barbieri is supported by the National Institute of Arthritis and Musculoskeletal and Skin Diseases of the National Institutes of Health under award number T32-AR-007465 and receives partial salary support through a Pfizer Fellowship grant to the Trustees of the University of Pennsylvania.

\section{Compliance with Ethical Standards:}

Conflict of Interest: Dr. Alexis Ogdie has received consulting payments from AbbVie, Amgen, BMS, Corrona, Lilly, Novartis, Pfizer, and Takeda and has received grants from Novartis and Pfizer. The authors have no other conflicts of interest to disclose.

\section{REFERENCES}

1. Mitchell AP, Winn AN, Dusetzina SB. Pharmaceutical Industry Payments and Oncologists' Selection of Targeted Cancer Therapies in Medicare Beneficiaries. JAMA Intern Med. April 2018.

2. DeJong C, Aguilar T, Tseng CW, Lin GA, Boscardin WJ, Dudley RA. Pharmaceutical Industry Sponsored Meals and Physician Prescribing Patterns for Medicare Beneficiaries. JAMA Intern Med. 2016;176(8):1114-1122.

3. Brax H, Fadlallah R, Al-Khaled L, et al. Association between physicians' interaction with pharmaceutical companies and their clinical practices: A systematic review and metaanalysis. PLoS One. 2017;12(4):e0175493.

4. Perlis RH, Perlis CS. Physician Payments from Industry Are Associated with Greater Medicare Part D Prescribing Costs. PLoS One. 2016;11(5):e0155474.

5. Shepherd JM. Biologic Drugs, Biosimilars, and Barriers to Entry. Health Matrix Clevel. 2015;25:139-61.

6. Hughes E. The Opioid that Made a Fortune for Its Maker — and for Its Prescribers. The New York Times. https://www.nytimes.com/interactive/ 2018/05/02/magazine/money-issue-insys-opioids-kickbacks.html, https://www.nytimes.com/interactive/2018/05/02/magazine/money-issue-insys-opioids-kickbacks.html. Published May 2, 2018. Accessed August $28,2018$. 